\title{
Incomplete family as a factor of crime in adolescents and youth
}

\author{
Galina Kantemirova, ${ }^{1, *}$ \\ ${ }^{1}$ North-Ossetian State University, Faculty of Sociology and Social Work, 362020, 44-46 Vatutina str., \\ Vladikavkaz, Russia
}

\begin{abstract}
This work is devoted to one of the most important problems of our time, the problem of juvenile delinquency. The study of juvenile delinquency now has a special significance, since in many regions of our country the percentage of crimes committed by adolescents and young people is quite large, the crime rate is on the rise. The article aims to address the problem and the causes of crime. The publication touches on the topic of crime in the youth and adolescent families. Particular attention is paid by the author to the fact that the family is the main factor in the upbringing and socialization of children. Considerable attention is paid to an incomplete family, as a factor and a source of increased criminality.

It is important not only to find out what are the causes of the increase in crime in adolescents and youth, but also to understand which preventive measures are the most effective one in combating crime.
\end{abstract}

Since ancient, a person has always been striving to study of his/her essence and destiny in the world. The search of a person of his/her "I" affects both the personal and professional spheres of development. From the point of view of the development of spirituality, it is natural for a person to go through several stages: the cognition of oneself, the cognition of the world, and the search for one's place in the world. And if the environment in which a person exists favors conditions for his ther personal growth, if he/she is free in his/her choice, all his actions are directed to the channel of creativity, which "is the main law of evolution" [11].

From immemorial times, the family was the most important element in people's lives and, undoubtedly, the whole society. The creation of such an alliance was very long and carefully prepared. It so happened that both parents bring their own contribution to the development and upbringing of the mind and consciousness of children. From each of the parents, the child adopts a certain pattern of behavior that he/she uses in the future. Unfortunately, in everyday life there are many examples of incomplete families. This, in turn, cannot but affect the structure and quality of the whole society, this deviation causes many consequences, one of which is the criminalization of youth and adolescents [12]. Since the educational potential of an incomplete family in which there is a teenager is limited pedagogically and psychologically, the child can be influenced by friends, with whom he/she often spends time.

\footnotetext{
* Corresponding author: Cantem.galina @ yandex.ru
} 
According to the research of demographers, this phenomenon is caused by the appearance of a new stage between adolescence and maturity, connected with the "search for oneself," which is called by D. Arnett the "emerging adulthood," as a result of which the society and the family receive a new social challenge associated with increasing economic burden on parents with adult children. At the same time, as staff members of socio-political studies of the Russian Academy of Sciences, Yu. A. Zubok and V. I. Chuprov point out, "There are always risks associated with the incompatibility of studies with work (or both) and the satisfaction of their cultural demands. In public life, in the process of transferring cultures, contradictions between material and spiritual production accumulate, especially when inefficient social policies [3].

In the modern world, a greater number of state programs are given a youth orientation. This is due to the fact that young people are at risk and influenced by the people around them, they are emotionally unstable, besides this the state is also unable to provide them with economic stability. All of the above affects the emergence and spread of such a phenomenon as the criminalization of youth and adolescents.

Youth and adolescent crime is a large and dangerous criminal phenomenon, which is often accompanied by negative structural changes. Most often, it is the youth and adolescents who commit the most dangerous crimes. They also tend to both create and participate in organized, armed criminal groups that carry out the most daring crimes. In the scientific literature, there are various classifications of youth crime, based on the age criterion. In criminal practice, the classification of youth crime is divided into 2 large groups: (1) the "juvenile delinquency" age group from 14 to $18,(2)$ the "juvenile crime" age group from 18 to 29 years, and this category is subdivided in turn into 2 subgroups (1418 and 25-29) [8].

In the structure of the types of crime, young people are dominated by rape, robbery, and drug-related crimes. In younger criminal groups, crime is growing at a very fast pace, it is a process of rejuvenating crime. According to statistics, young people commit such offenses as:

1) Fight $-66 \%$,

2) Hooliganism - $50 \%$,

3) Theft $-45 \%$,

4) Extortion of money $-35 \%$,

5) Brigandage $-15 \%$,

6) Fraud - 14\% [4].

In order to understand the spread of crime, it is necessary to pay attention to the identity of the criminal, the type of family in which he/she grew up, to consider the phenomenon of criminalization at the level of unity.

The identity of the offender is the person who committed the crime, in which his/her antisocial orientation emerged, expressing the negative properties that affect the nature of criminal behavior with external conditions. In contemporary criminology, more cases of crimes are committed by women, there is a tendency to change the gender picture of crimes. The contingent of criminals is allocated from all mass of people due to the selection of persons, with a certain set of parameters. Signs that can contribute to the formation of abnormal behavior include the presence of a number of problems, ranging from education in incomplete or dysfunctional families, the presence of the offender's own family, the frequency of the conflicts that arise, and emotional instability. Also, the most common sign among all criminals is, as a rule, the lack of higher education $[9,1]$.

An analysis of the ratio of female and male persons among juvenile offenders shows that among them predominate males (over 90\%) [12], which is due to their different social roles and experiences, psychophysiological characteristics, etc. At the same time, it should be noted that there is a process of criminalization of female representatives: in the criminal 
behavior of underage girls, the audacity, aggressiveness, cynicism are increased, all of which is manifested, on the one hand, in increasing the intensity of criminal activities of these individuals; on the other hand, in ways of committing crimes. Both the social determinants and the physiological characteristics of female minors predetermine the existence of a number of features of the types of crimes that they commit. In the structure of juvenile delinquency, almost half the number of murders is observed; 2.5 times the number of crimes related to the illegal circulation of weapons, narcotic drugs, and psychotropic substances can be identified, and the bulk of crimes committed by this category of persons constitute thefts [7, p. 59].

Based on the data on the composition of the family we obtained in the course of studying criminal cases, we can come to the conclusion that adolescents and young people on the path of crime, for the most part, were brought up in more difficult conditions than their law-abiding counterparts. Thus, $62.3 \%$ of female criminals and $52.9 \%$ of young male criminals live in a broken or not created family (divorce, birth of a child out of wedlock, etc.). In addition, almost one-quarter of the $23.8 \%$ of parents of teenage offenders themselves grew up in single-parent families.

The financial situation of an incomplete parental family is always worse than in the full. According to the results of a study of incomplete families, in which minor criminals were brought up, the main reason for the absence of one of the parents is a divorce $[4,7,9,10$, 12]. In such circumstances, they actively oppose the attempts of their mothers or fathers to create a family anew, conflict with their parents about this. In families of this type, the emotional closeness of the parent and the child is disturbed, and the aggressiveness and cruelty are manifested in the behavior of the younger. Trying to show their protest to the mother or father, teenagers overstep the norms of morality, and sometimes commit crimes. It is no accident that $40.9 \%$ of female criminals and $28.9 \%$ of young male criminals came from families where their mother and stepfather were not engaged in their education, or father and stepmother.

It should be noted that the problems of an incomplete family need serious analysis. The study found that in $38 \%$ of complete families, in which minors violated the law, fathers drank. In this connection, it should be recognized that in the formation of the personality of a teenager, a large criminal role is played equally by the fact of living in a disintegrated or uncreated family, as well as living in a full family, which usually has a drinking father. It can be argued that in a number of cases, the family ceases to be unprofitable from the educational point of view precisely as a result of a divorce [6].

In recent years, the modern family has undergone yet another change. There was a new trend in the society, the distribution was given to single-child families. Criminological studies have shown that reducing the number of children in the family contributes to an increase in the number of "difficult" adolescents and juvenile offenders of law [4].

In such families, children are usually capricious and spoiled, their selfishness and selfish goals are often manifested in relation to others, they tend to show cruelty and indifference in fights and robberies.

Studies have revealed that in families with one child, every fourth $(26.9 \%)$ youth and one third (34.1\%) of girls who have committed crimes were brought up. While the majority $(63.2 \%)$ of law-abiding teenagers were brought up in the family together with their sister or brother.

According to the results of the survey, $43.5 \%$ of the boys and $50.0 \%$ of the girls who committed the crime were raised in families that experienced material difficulties. Among their peers from the control group, this indicator of family unhappiness is six times less frequent (only $7.8 \%$ of families).

As to be expected, the study shows an increase in the criminality of families of juvenile offenders. Each fourth (26.9\%) of the females and every fifth $(19.2 \%)$ of the young males 
who committed the crime had a previous conviction, every eighth $(12.1 \%)$ female and every eleventh $(8.8 \%)$ male had such a mother. In the family of every sixth juvenile offender ( $15.9 \%$ of boys and $17.3 \%$ of girls), the brother has a criminal record. Quite often in families of teenagers who committed a crime, previously convicted were sisters, as well as grandparents $(9.1 \%$ of males and $17.4 \%$ of females). Only $1.7 \%$ of them had a previously convicted father and the same number had a previously convicted sister, $3.4 \%$ previously convicted grandparents, and $2.6 \%$ - previously convicted brother. Previously convicted mothers in families of law-abiding teenagers were not identified [10].

Extreme measures, such as deprivation of parental rights, as well as a restriction on legal capacity, were applied against $6.9 \%$ of mothers and $5.4 \%$ of fathers of male criminals and against $10.5 \%$ of mothers and $7.1 \%$ of fathers of female criminals.

In the control group, there were significantly fewer such cases: $1.3 \%$ of adolescents were deprived of parental rights by the father, and $0.4 \%$ had a limited ability to act as a mother. Depriving parental rights is always an extreme measure. Nothing can replace a child's parental affection, kindness, and humanity of the mother [2].

Teenagers often take to heart a break with their parents, especially with the mother, who plays an initial role in the formation of their personality [5]. Separation from parents causes them a strong psychological trauma, provokes further deformations of their personality and, under certain conditions, inevitably leads to the commission of a crime. Parents should always pay maximum attention to the moral upbringing of children, the formation of a system of values of life, to teach them to literature and culture, to instill in children a sense of humanity and responsibility for both actions towards oneself and others. At school and at home, children should be explained by the legal and regulatory framework of our state so that children are aware of the consequences of offenses, which in the future could reduce the overall statistics of the number of all offenses. Parents should be aware of the seriousness of the marriage, help their children to know our world, create a favorable environment for the family to form a healthy and stable psyche of the child.

The main solution to this set of problems is the state youth policy, which is based on the socio-economic and moral support of youth from the state and society. Its tasks include providing affordable education, creating conditions for upbringing, preserving the health and employment of young people. The communal prevention connected with the organization of closely residing people who keep in touch with the police and regulate the maintenance of public order on their territory is also interesting in solving this problem. Collectively, the "community" provides protection, organization of leisure for young people, care for socially vulnerable neighbors. In addition, it is advisable to introduce moral education programs as a supplement to alternative punishments, using the experience of other countries, such as the United States and France, regarding prisoners serving sentences in places of deprivation of liberty [2].

Priority areas of the basic (primary) general social prevention should be measures to actually observe the basic human rights, ensure its security, provide each real opportunity for satisfaction in creativity, self-affirmation through positive, useful deeds. And also the assistance of the state and the progressive forces of society in reducing the excessive gap between the material security of an ultra-rich minority and a fledgling majority [11]. In order to improve the prevention of juvenile and youth crime, the Ministry of Education and Science of the Russian Federation, in conjunction with the Ministry of Internal Affairs of Russia, should provide special courses in the system of educational institutions for the training of specialists in the field of criminological prevention among minors and young people, orienting, in carrying out preventive work for preventive pedagogy, and special prevention of crimes of students of adolescents and youth [1, p. 167].

In summary, it must be said that every effort should be made to improve preventive measures and combat juvenile and youth crime. First and foremost, it is necessary to 
toughen the criminal prosecution of adults, who involve teenagers in criminal relationships, and also adversely affect them morally and physically. Do not forget about the development and preservation of youth sports clubs, clubs on interests and circles, the promotion of legal foundations in educational institutions and the media. Comprehensive measures are needed to improve the life and safety of young people, they need to guarantee a bright future, so that many of the young people do not go on a slippery road in anticipation of a quick receipt of money.

The contemporary society faced a catastrophically rapid growth and radical changes in the structure and nature of crime among minors and youth. Is the society ready for such changes? This issue is very relevant because this crime, in comparison with the adult, is characterized by a high degree of activity and dynamism. People who have embarked on the path of committing crimes at a young age are difficult to correct and reeducate and constitute a reserve for adult crime. Juvenile delinquency, with a large scale of distribution, requires decisive, vigorous and targeted measures to prevent it.

\section{References}

1. T. M. Zayko, Organizational and legal basis of activities of the specialized agencies for the prevention of juvenile delinquency (Izdatel'stvo Ural'skogo juridicheskogo instituta MVD Rossii Ekaterinburg, 2001)

2. A. N. Lee, Problems of juvenile delinquency prevention: a tutorial (Norma, Moscow, 2015)

3. V. G. Dobrokhleb, The present and future of the family in a changing world: a collective monograph (Econ-Inform Publishing House, Moscow, 2015)

4. V. N. Kudryavtsev, Criminology (Norma, Moscow, 2015)

5. G. A. Kantemirova, Sociology of the City, 2 (2015)

6. E. Grigorieva, Family and School, 4 (2015)

7. I. P. Bashkatov, Psychology of asocial-criminal groups of adolescents and youth (MGSU, Moscow, 2012)

8. N. I. Vetrov, Prevention of violations among youth: a training manual (Triada, Moscow, 2017)

9. Yu. M. Antonyan, The person of the criminal: a training manual (Yurayt, Moscow, 2013)

10. Yu. R. Orlova, Problems of juvenile delinquency: a teaching aid (Smolensk region IPA, Moscow, 2017)

11. Ya. Gilinsky, Journal of Criminalistics, 2, 7 (2010)

12. J. Roark, K. E. Knight, H. Olson, H. DeSandre, Crime \& Delinquency, 63, 13 (2017) 